\title{
CONOCIMIENTO PROFESIONAL Y EPISTEMOLOGÍA DE LOS PROFESORES, II: ESTUDIOS EMPÍRICOS Y CONCLUSIONES
}

\author{
PORLÁN ARIZA, R., ${ }^{1}$ RIVERO GARCÍA, A. ${ }^{1}$ y MARTín DEL POZO, R. ${ }^{2}$ \\ 1 Departamento de Didáctica de las Ciencias. Universidad de Sevilla. \\ 2 Departamento de Didáctica de las Ciencias Experimentales. Universidad Complutense de Madrid. \\ Miembros del Grupo DIE (Didáctica e Investigación Escolar) y del Proyecto Curricular IRES \\ (Investigación y Renovación Escolar)*
}

\section{SUMMARY}

In a previous paper we discuss the theoretic and methodological framework which we have considered for studying the professional knowledge of the teachers. In this paper we present a review of some empirical studies with significance to the analysis of the scientific and didactic conceptions of the teachers. We also present a synthesis of the data obtained by the authors of these studies as well as of the most important conclusions.

\section{INTRODUCCIÓN}

Nuestro trabajo acerca del contenido de las concepciones de los profesores sobre la ciencia, la enseñanza y el aprendizaje está fundamentado en tres consideraciones:

a) El conocimiento profesional «de hecho» sobre el conocimiento escolar influye poderosamente en la manera de interpretar y actuar en la enseñanza.

b) El conocimiento profesional deseable es un conocimiento epistemológicamente diferenciado, resultado de una reelaboración e integración de diferentes saberes, que puede concebirse como un sistema de ideas en evolución (lo que permite una gradación de lo simple a lo complejo: una hipótesis de progresión que facilite dicha evolución).

c) El conocimiento profesional deseable es un conocimiento «interesado», puesto que contiene determinadas actitudes y valores encaminadas a la transformación del contexto escolar y profesional.

En definitiva, con estas consideraciones estamos aludiendo a las perspectivas constructivista, compleja y crítica que fundamentan nuestro trabajo y que ya han sido tratadas en el artículo anterior.

Este marco teórico de referencia obliga, por pura coherencia, a describir e interpretar las concepciones de los profesores. Pero no se trata únicamente de poder contrastar las hipótesis y los resultados obtenidos con los instrumentos presentados en el primer artículo. Para nosotros se trata también de poder intervenir, de una manera fundamentada, en la práctica de la formación (inicial y permanente) de los profesores. Al igual que ocurre en el caso de las concepciones de los alumnos, resulta coherente, desde una posición constructivista, 
considerar las concepciones de los profesores como eje vertebrador del proceso formativo (Porlán y López, 1993; Gil, 1993).

Por todo ello, nos parece conveniente analizar, en primer lugar, algunos estudios que aportan una información valiosa acerca del contenido de las concepciones científicas y didácticas de los profesores. Posteriormente ofreceremos nuestra visión, a partir de los resultados obtenidos en las investigaciones que hemos realizado en los últimos años. Con ello pondremos de manifiesto la diversidad de concepciones detectadas, lo que nos servirá para ir apreciando diferentes niveles en la formulación del conocimiento profesional deseable.

\section{LOS ESTUDIOS SOBRE LAS CONCEP- CIONES CIENTIFICAS Y DIDACTICAS DE LOS PROFESORES}

Si bien inicialmente se prestó una mayor atención a los aspectos procesuales y estructurales del pensamiento del profesor (Porlán, 1995), en los últimos años ha habido un mayor interés por describir y analizar el contenido de sus concepciones. Dado que nuestro interés también se centra en dicho contenido, hemos diferenciado y seleccionado, para su posterior descripción y análisis, tres tipos de estudios:

a) Los que se centran en las ideas de los profesores acerca del conocimiento científico (naturaleza, estatus, relación con otros conocimientos, modo de producción, cambio, etc.).

b) Los que se refieren a las creencias pedagógicas que, como veremos, incluyen un amplio repertorio de aspectos relacionados con la enseñanza y el aprendizaje en el contexto escolar.

c) Los que tratan de establecer relaciones entre el conocimiento y su construcción y transmisión en el contexto escolar. Es decir, aproximarse a la epistemología de lo escolar que sustentan los profesores (Pope y Scott, 1983; Porlán, 1989).

1. Por lo que respecta a las concepciones sobre la ciencia, numerosos autores (Pope y Gilbert, 1983; Gordon, 1984; Gil, 1991; Lederman, 1992; Kouladis y Ogborn, 1995) insisten en que los profesores transmiten una imagen deformada del conocimiento y del trabajo científico que poco tiene que ver con las recientes aportaciones de la epistemología de la ciencia, si bien se reconoce que ello no es exclusivo del medio escolar.

Según Gordon (1984), esta imagen deformada presenta la ciencia como algo acabado, cierto y en constante avance, y a los científicos como seres de inteligencia superior. Este autor va más allá del contexto escolar y plantea que los medios de comunicación y el lenguaje cotidiano también contribuyen poderosamente a difun- dir en la sociedad tres grandes mitos: el del progreso científico, el de lo científico como razonable y verdadero y el de la infalibilidad de los expertos.

En uno de los primeros estudios empíricos realizados al respecto, Cotham y Smith (1981) utilizaron un cuestionario (Conceptions of Scientific Theories Test) con cuatro dimensiones (las implicaciones ontológicas, la génesis, la elección y la comprobación de teorías) que permiten, cada una de ellas, dos alternativas epistemológicas (realismo/instrumentalismo, inductivismo/ invención, objetivismo/subjetivismo y tentavismo/conclusionismo, respectivamente). Los datos señalan que los profesores de primaria de la muestra son conclusivistas a la hora de comprobar las teorías, inductivistas para explicar cómo se genera el conocimiento científico y objetivistas para elegir entre teorías que rivalizan.

En este mismo sentido, en la reciente revisión efectuada por Lederman (1992), y también en nuestras últimas revisiones (Martín, 1994; Porlán, 1995; Porlán y Martín, 1996), se pone de manifiesto una tendencia mayoritaria entre los profesores y estudiantes de profesores: la visión positivista (empiroinductivista) de la ciencia. Sin embargo, una de las conclusiones del estudio de Kouladis y Ogborn (1989) es que existen evidencias de otros puntos de vista sobre el conocimiento científico, que constituyen una cierta evolución desde esta imagen empiroinductivista hacia planteamientos más contextualizados. Nuestros propios resultados, como veremos más adelante, se sitúan en esta misma dirección.

En el mencionado estudio de Kouladis y Ogborn (1989) se trabajó con una muestra de 12 profesores de ciencias y 11 estudiantes-profesores, los cuales respondieron a un cuestionario de 16 ítems de opción múltiple sobre diferentes aspectos del conocimiento científico: el método científico, los criterios para diferenciar ciencia de no-ciencia, el cambio en el conocimiento científico y su estatus. Los diferentes tipos de respuesta obtenidos se corresponden con tendencias básicas en la filosofía de la ciencia: inductivismo, hipotético-deductivismo, contextualismo (tanto en su versión racionalista como relativista) y relativismo. No obstante, el análisis de los resultados hizo necesario incluir otra categoría, que los autores denominaron eclecticismo, en la que se encuadraba el $40 \%$ de la muestra. La correlación entre las diferentes posiciones que se detectaron revelan tres posibles puntos de vista diferentes sobre la ciencia:

a) En el primero se incluye a los que mantienen una posición inductivista respecto a la metodología científica, pero que tienden a ser racionalistas en la diferenciación de lo que es y no es ciencia y relativistas respecto al estatus del conocimiento científico.

b) En el segundo, el contextualismo metodológico se asocia con una postura racionalista indecisa respecto al estatus del conocimiento científico, mientras que los sujetos tienden a adoptar un contextualismo relativista para explicar el cambio en dicho conocimiento. 
c) En el tercero se da en todos los aspectos estudiados una posición ecléctica.

Como indican los propios autores, las diferencias respecto a otros estudios, donde predominan los enfoques absolutistas y positivistas, pueden deberse a la diferencia de edad y experiencia (se trataba de profesores jóvenes y estudiantes de profesores) y, muy especialmente, a la influencia del currículo formativo, que es más acorde con planteamientos relativistas.

Por último, se debe señalar que en el mencionado trabajo de revisión de Lederman (1992) se sugiere que estas investigaciones deben llevarse a cabo también durante el desarrollo en el aula de temáticas concretas, para así poder indagar acerca de cuáles son las creencias que, sobre la naturaleza de la ciencia, tienen mayor influencia en la enseñanza. En este sentido, para Pope y Scott (1983), tanto los contenidos como los métodos que se utilizan mayoritariamente en la enseñanza favorecen en los alumnos una visión acumulativa y objetiva del conocimiento científico, una imagen de las ciencias experimentales como ciencias prototípicas y una visión inductivista de la metodología científica. Pero antes de adentrarnos en estas relaciones, veamos qué panorámica nos muestran los estudios sobre las creencias en torno a la enseñanza.

2. En un trabajo de revision sobre los primeros estudios acerca del contenido de las concepciones didácticas de los profesores (Porlán, 1989) distinguimos tres enfoques diferentes:

a) Un enfoque cientifista, preocupado por la generalizacion de los resultados obtenidos con muestras grandes, cuestionarios proposicionales y enfoques metodológicos cuantitativos (análisis multifactoriales). Ejemplos representativos son los trabajos de Wehling y Charters (1969) y Victor (1976) con el Cuestionario de concepciones del profesor sobre el proceso educativo. En el primero se detectaron hasta ocho dimensiones o conjunto de creencias, que se referían a diferentes aspectos particulares de la enseñanza (el valor de los contenidos, el orden en la clase, etc.), mientras que en el segundo se establecieron, además, relaciones entre dichas dimensiones, detectándose tres modelos pedagógicos más generales: uno centrado en el profesor, otro centrado en los alumnos y un tercero que hacía referencia a la dicotomía entre autonomía del alumno y control del profesor.

En esta misma línea, el trabajo de Bauch (1984) estudia las posibles relaciones entre las creencias y las conductas del profesor, a partir de los datos de un Inventario de creencias docentes (en torno al control del profesor y a la participación de los alumnos) y de las observaciones de clases. Los resultados sugieren una clasificación de los profesores en dos grupos: uno centrado en el control de la clase (cercano a lo que suele denominarse un profesor transmisivo, centrado en los contenidos, en el marco de un modelo didáctico tradicional) y otro preocupado por la participación de los alumnos, que diversifica las estrategias metodológicas para llevar a cabo un proceso crítico de socialización.
Por último, Halkes y Deijkers (1983) realizaron una interesante recopilación de información sobre el contenido del pensamiento pedagógico de los profesores (que denominaron criterios subjetivos de enseñanza), que sirvió de base para confeccionar un cuestionario y que fue sometido a diferentes controles. Pasado a distintas muestras de profesores, los resultados ponen de relieve tres núcleos esenciales de concepciones sobre la enseñanza: el control del profesor, la participación de los estudiantes y el flujo de las actividades.

b) Un enfoque interpretativo, más interesado en profundizar en las creencias que mantienen muestras muy reducidas de sujetos (hasta de un solo profesor), utilizando metodologías cualitativas para el análisis de los datos obtenidos mediante entrevistas, cuestionarios de preguntas abiertas, diarios, otras producciones escritas, observaciones de clase, etc. Por ejemplo, Elbaz (1981) realiza una descripción en profundidad del conocimiento práctico de una profesora, cuyo contenido hace referencia a cinco categorías: el contenido de la asignatura, las características del currículo, el estilo de enseñanza, el ambiente escolar y la imagen de sí mismo.

Con este mismo enfoque, Buitnik y Kemme (1986) desarrollan el concepto de teoría educativa subjetiva para describir las justificaciones que una muestra de seis futuros profesores daban de sus propias actuaciones en situación de prácticas. Sus principales conclusiones señalan el carácter global y relativamente estático de estas teorías, puesto que sólo cambian en la medida en que se perciben como inadecuadas para la práctica.

c) Un enfoque crítico, con el que nos identificamos en buena medida, que utiliza la investigación como ayuda para transformar la práctica de los profesores. Como ejemplo de este enfoque podemos referirnos al trabajo de Oberg (1986), que utiliza la técnica del repertorio de parrilla de Kelly para tratar de definir los constructos subyacentes a la práctica profesional. Para ello solicitó a 19 profesores que escribieran sobre su práctica. Las categorías que se definieron (el papel del profesor, el aprendizaje, la enseñanza, el alumno y los contenidos) se utilizaron a su vez para estudiar la práctica de uno de ellos en profundidad. La autora transformó la lista de constructos hipotéticos en una serie de principios organizados que sirvieron de base para orientarle en la reflexión crítica sobre su práctica, al tiempo que las categorías y constructos detectados sirvieron para organizar y analizar las concepciones de otros profesores.

Más recientemente, en nuestro país, destacan los trabajos de Barquín (1991) y Pérez y Gimeno (1992). El Cuestionario de opiniones pedagógicas es el instrumento utilizado por estos autores con amplias muestras de futuros profesores y profesores en activo, tanto de primaria como de secundaria. Dicho cuestionario consta de 11 ámbitos (por ejemplo: la selección y organización de los contenidos, la naturaleza del conocimiento, etc.) que intentan dar cuenta de los procesos de enseñanza-aprendizaje en el contexto escolar. Como desarrollo de estos ámbitos se plantean 34 dimensiones que contienen, finalmente, 119 declaraciones, sobre las que los sujetos 
deben manifestar su grado de acuerdo o desacuerdo. De los abundantes resultados de estos estudios nos interesa resaltar que en las dimensiones que se refieren a cuestiones curriculares, muy especialmente las relacionadas con el contenido, aparecen diferencias significativas entre las distintas muestras; mientras que, en las dimensiones que tienen un carácter más ideológico, no se detectan diferencias significativas entre los profesores en formación y en activo. Los contenidos, tal como señala Barquín (1991), constituyen un núcleo de problemas muy diversos que a lo largo de la carrera parecen evolucionar hacia soluciones tradicionales y academicistas (p. 254). Dichas soluciones podemos caracterizarlas por la primacía de lo lógico frente a lo psicológico a la hora de establecer los criterios de selección y organización, inadecuación al contexto sociocultural del alumno, falta de ruptura con el academicismo y visión objetivista y neutral del conocimiento.

Por otra parte, Marrero (1994) ha estudiado las teorías implícitas del profesorado a partir de un cuestionario con proposiciones que caracterizan a cada una de las grandes corrientes pedagógicas (tradicional, activa, crítica, técnica y constructivista). Los análisis factoriales realizados ponen de manifiesto la síntesis particular que un centenar de profesores de EGB y de instituto hacen de la cultura pedagógica disponible. Los resultados muestran:

a) Una teoría implícita dependiente, que caracteriza la enseñanza como una actividad que depende de los contenidos, del profesor y de unos determinados valores impuestos.

b) Una teoría implícita productiva, en la que la enseñanza es una actividad que busca la eficacia en el aprendizaje a partir de los objetivos y de su evaluación.

c) Una teoría implícita expresiva, en la que la actividad del alumno y sus intereses se convierten en el núcleo esencial de la enseñanza.

d) Una teoría implícita interpretativa, en la que se combina la importancia de atender a las necesidades, intereses y evaluación del aprendizaje de los alumnos con la necesidad de analizar rigurosamente el trabajo docente.

e) Una teoría implícita emancipatoria, en la que se resalta el carácter ideológico de la enseñanza y su intencionalidad crítica.

En otra muestra de 139 profesores de EGB analizada por Marrero, al menos la mitad de la muestra estudiada tenía tendencias conservadoras ligeramente cargadas de activismo más o menos centrado en el alumno, mientras que la otra parte del profesorado sostiene una actitud más progresista sin llegar a ser radical (p. 262).

En definitiva, la revisión de los estudios empíricos mencionados sobre las concepciones didácticas nos muestra una tendencia mayoritaria a concebir la en- señanza como una actividad centrada en la explicación del profesor, con los contenidos como eje director de la dinámica de la clase, y controlada y dirigida por el profesor. Desde nuestro punto de vista, estos datos reafirman la evidencia cotidiana de que en la escuela predomina aún la enseñanza que solemos denominar tradicional (Porlán, 1995, p.11). Pero, al mismo tiempo, los datos también revelan creencias y prácticas alternativas a la enseñanza tradicional que, además de ser minoritarias, no son tan «consistentes». En otras palabras, hemos de ser conscientes de que no existe en la práctica educativa un referente curricular con suficiente tradición como para poder desplazar a corto plazo las tendencias más tradicionales (Porlán, 1993, p.160). De ahí la necesidad de reivindicar espacios y tiempos para poder llevar a la práctica planteamientos alternativos a los que, hoy por hoy, siguen siendo predominantes.

3. Para concluir esta revisión, vamos a hacer referencia a aquellos trabajos que tratan de relacionar las concepciones científicas y didácticas de los profesores. En la mayoría de los casos se trata de muestras constituidas por profesores de ciencias (en formación o en activo) y se utiliza un enfoque plurimetodológico que busca el contraste de los datos obtenidos a través de diferentes instrumentos. Entendemos que el trabajo de Pope y Scott (1983), con el que nos identificamos, es un claro precursor en el estudio de la epistemología del profesor, de sus creencias sobre el conocimiento, y su construcción y transmisión en el contexto escolar. La hipótesis central de estos autores considera que: la concepción positivista y empiroinductivista de las ciencias está en consonancia con la versión absolutista de la verdad y del conocimiento. Así, los profesores que sostienen esta concepción de la ciencia, del contenido del currículo y de la manera de enseñar a los estudiantes pondrán poco o ningún énfasis en sus concepciones y en su participación activa (Pope y Gilbert, 1983, pp. 76-77, versión en castellano). Con la pretensión de analizar el contenido de las relaciones entre concepciones científicas y didácticas, hemos seleccionado algunos de los estudios más representativos, que pasamos a comentar.

El estudio de Hollon y Anderson (1987) se focaliza en las concepciones de profesores de ciencias sobre la enseñanza y el aprendizaje de los conceptos científicos, pero sus conclusiones nos proporcionan puntos de vista que, como se verá, aclaran algunas de las tendencias ya descritas. Las tres concepciones detectadas en la muestra de 13 profesores fueron las siguientes:

a) Orientación de desarrollo conceptual, basada en la consideración de las ideas de los alumnos sobre los conceptos de ciencias. La interacción entre dichas ideas y la explicación del profesor es el elemento fundamental para lograr el aprendizaje.

b) Orientación de comprensión del contenido, basada en la asimilación de nuevos conocimientos que se añaden, completan o corrigen a los que ya tiene el alumno a partir, sobre todo, de las explicaciones del profesor. 
c) Orientación de adquisición factual, basada en la consideración de los intereses y necesidades de los alumnos, pero no en el trabajo didáctico con sus ideas sobre los conceptos de ciencias. El profesor suministra los materiales para que los alumnos realicen las actividades encaminadas al aprendizaje conceptual, pero, a diferencia de las otras dos orientaciones, no se propicia la discusión o la explicación de conceptos.

Aguirre, Haggerty y Linder (1990) trabajaron con una muestra de 74 estudiantes-profesores de ciencias, a los que pasaron un cuestionario de preguntas abiertas sobre la ciencia, su enseñanza y su aprendizaje. El análisis cualitativo de las respuestas reveló una diversidad de concepciones sobre la ciencia, siendo la visión empirista mayoritaria entre los sujetos. Los autores distinguen:

a) Una concepción ingenua, que entiende la ciencia como un conjunto de explicaciones y observaciones acerca de cómo y por qué ocurren determinados fenómenos.

b) Una concepción experimental-inductiva en la que el conocimiento proviene de la observación y experimentación.

c) Una concepción experimental-falsacionista en la que se insiste en el papel de la experimentación para falsar las teorías científicas.

d) Una concepción tecnológica que reduce la ciencia a una actividad tecnológica encaminada a mejorar la calidad de vida.

e) Y, por último, una concepción de la ciencia como un proceso de tres fases (desarrollo, comprobación y aceptación de teorías por la comunidad científica).

Sobre la enseñanza, los estudiantes-profesores mantuvieron, casi por igual, estas dos concepciones:

a) El profesor como fuente de conocimientos y la enseñanza como transmisión de contenidos.

b) El profesor como guía y la enseñanza como actividad que influye o facilita la comprensión.

Por lo que respecta al aprendizaje, la concepción conocida como mente en blanco o tabla rasa resultó ser mayoritaria. No obstante, se detectaron, junto con ésta, las siguientes concepciones:

a) El aprendizaje como un intento de dar sentido a la nueva información en función de la comprensión previa existente.

\section{b) El aprendizaje como una respuesta afectiva.}

En sus conclusiones, estos autores insisten en que los estudiantes-profesores, antes de iniciar su formación, tienen una diversidad de puntos de vista sobre la ciencia, su enseñanza y su aprendizaje que han de tomarse en consideración en el proceso formativo. Por otra parte, aunque en este estudio no se relacionan entre sí de forma sistemática las diferentes categorías de análisis, se señala que la visión empirista de la ciencia puede significar, aunque parezca contradictorio, una disposición hacia la enseñanza transmisiva por parte de los futuros profesores.

En el estudio de Smith y Neale (1991) con profesores de ciencias de primaria, se detectaron cuatro tendencias diferentes en las que sí se relacionan las concepciones sobre la ciencia, su enseñanza y aprendizaje:

a) Tendencia basada en el descubrimiento: la ciencia se entiende como un proceso de indagación y la enseñanza como facilitadora del descubrimiento de los alumnos.

b) Tendencia basada en los procesos: la ciencia se elabora gracias al método científico y la enseñanza debe propiciar que los alumnos lo aprendan.

c) Tendencia basada en el dominio del contenido: la ciencia es un conjunto de datos, conceptos y teorías y la enseñanza debe presentarlo adecuadamente a los alumnos.

d) Tendencia basada en el cambio conceptual: la ciencia es una forma de conocimiento que se construye y evoluciona dentro de una ecología conceptual y la enseñanza debe facilitar la evolución de las ideas de los alumnos.

Las observaciones de clase, y las discusiones con profesores acerca de sus puntos de vista sobre la enseñanza, sirvieron a Gallagher (1993) para matizar algunas de las tendencias ya descritas y proponer seis puntos de vista acerca de la enseñanza de las ciencias:

a) La enseñanza como transmisión de información que es recogida por el que aprende. Para ello es suficiente que el profesor conozca el contenido que va a enseñar. Por eso, la profesión de profesor se considera un trabajo simple.

b) La enseñanza como contenido organizado; implica que el profesor realiza una actividad compleja de adaptación del contenido para que pueda ser «digerido» por los alumnos.

c) La enseñanza como conjunto de actividades manipulativas seleccionadas por el profesor para que los alumnos puedan descubrir el significado de los conceptos.

d) La enseñanza como un ciclo de aprendizaje que comienza por la exploración, la invención de una explicación para las observaciones realizadas y la aplicación de lo aprendido a otras situaciones.

e) La enseñanza como cambio conceptual que también requiere que los profesores sigan un ciclo. Comienza con la identificación de las ideas de los alumnos; continúa con la prestación de ayuda para que comprendan las ideas científicas, ya que éstas son diferentes pero también mejores que las iniciales; y acaba con el reemplazamiento de unas por otras. 
f) El aprendizaje como construcción y la enseñanza como guía. La cuestión central en este enfoque es que los profesores deben usar estrategias diversas para ayudar a los alumnos a dar sentido a las ideas que queremos que comprendan, a hacer conexiones entre ellas y a explicar su conocimiento.

Es precisamente el grado de responsabilidad que se da a los alumnos lo que diferencia estas tres últimas maneras de entender la enseñanza de las ciencias.

Finalmente, el autor advierte que se trata de un proceso lento y nada fácil y que implica cambios profundos en las concepciones de los profesores sobre el conocimiento, la enseñanza y el aprendizaje.

Por su parte, Gustafson y Rowell (1995) estudiaron las concepciones sobre la ciencia, la enseñanza y el aprendizaje en una muestra de 27 futuros profesores, utilizando, como instrumento, cuestionarios de preguntas abiertas y entrevistas semiestructuradas. Dichos instrumentos se aplicaron antes y después de dos cursos sobre el currículo de ciencias, en los que se discutió el punto de vista constructivista sobre el aprendizaje de las ciencias y sus implicaciones en la enseñanza. Los resultados ponen de manifiesto que:

a) Los estudiantes-profesores siguen pensando que los alumnos aprenden a partir de procesos de manipulación

b) En coherencia con esta forma de entender el aprendizaje, la estrategia de enseñanza más efectiva es proponer a los alumnos actividades prácticas. Sin embargo, una vez realizado el curso, la mayoría de los futuros profesores pusieron el acento en basar la enseñanza en las ideas de los alumnos. c) La ciencia se concibe como un cuerpo de conocimientos que se adquiere mediante un determinado proceso de búsqueda. Los autores llaman la atención sobre la persistencia de este planteamiento una vez finalizados los cursos.

En un reciente estudio, Hashweh (1996) analiza los efectos de las creencias epistemológicas de los profesores de ciencias en la enseñanza. Más concretamente, su hipótesis central es que los profesores con creencias de tipo constructivista, frente a los que las tienen empiristas, están más capacitados para:

a) detectar las concepciones alternativas de los estudiantes;

b) llevar a cabo un variado repertorio de estrategias de enseñanza;

c) usar más estrategias para inducir el cambio conceptual;

d) y utilizar más frecuentemente estrategias de enseñanza potencialmente efectivas.

Para ello, el autor compara las creencias de una muestra de 35 profesores de ciencias, clasificados previamente en dos grupos (constructivistas y empiristas) según sus concepciones sobre el conocimiento y el aprendizaje. El instrumento utilizado es un cuestionario que consta de tres partes:

a) En la primera se plantean dos incidentes críticos sobre los que los profesores han de tomar partido.

b) En la segunda se les interroga sobre qué hacer con las concepciones de los estudiantes.

Estudios realizados por los autores sobre las concepciones epistemológicas de los profesores.

\begin{tabular}{|c|c|c|c|}
\hline ESTUDIOS & MUESTRAS & INSTRUMENTOS & TÉCNICAS \\
\hline $\begin{array}{l}\text { ESTUDIO } 1 \\
\text { (Porlán, 1989, 1994) }\end{array}$ & 7 futuros profesores de EGB & $\begin{array}{l}\text { Entrevistas } \\
\text { Informes escritos } \\
\text { (Diario de prácticas) }\end{array}$ & Análisis de contenido \\
\hline $\begin{array}{l}\text { ESTUDIO 2 } \\
\text { (Porlán, 1989) }\end{array}$ & $\begin{array}{l}107 \text { futuros profesores de EGB } \\
158 \text { profesores de EGB }\end{array}$ & $\begin{array}{l}\text { Inventario de creencias } \\
\text { pedagógicas y científicas } \\
\text { (INPECIP) }\end{array}$ & $\begin{array}{l}\text { Análisis de componentes } \\
\text { principales }\end{array}$ \\
\hline $\begin{array}{l}\text { ESTUDIO } 3 \\
\text { (Martín, 1994) }\end{array}$ & 24 futuros profesores de EGB & INPECIP & $\begin{array}{l}\text { Análisis de componentes } \\
\text { principales }\end{array}$ \\
\hline $\begin{array}{l}\text { ESTUDIO } 4 \\
\text { (Martín, 1994) }\end{array}$ & $\begin{array}{l}6 \text { grupos de } 4 \text { futuros } \\
\text { profesores de EGB }\end{array}$ & $\begin{array}{l}\text { Informes escritos } \\
\text { (Diseño de una unidad didáctica) }\end{array}$ & Análisis de contenido \\
\hline
\end{tabular}


c) En la tercera deben valorar seis estrategias (explicar, repetir, convencer, refutar, desarrollar y reestructurar).

El resultado general de este estudio pone de manifiesto que los profesores con creencias constructivistas están más preparados que los empiristas para inducir un cambio conceptual persistente, porque ésa es su idea del proceso de enseñanza-aprendizaje que conciben las concepciones de los alumnos como un conocimiento alternativo y utilizan estrategias variadas para promover el cambio. Por su parte, los profesores con creencias de tipo empirista entienden las ideas de los alumnos como errores y utilizan muchas menos estrategias para tratar de modificarlas.

En definitiva, los datos empíricos nos ofrecen una diversidad de concepciones que, en la medida en que ponen en relación más variables, nos acercan a una cierta visión de la epistemología que manifiestan los profesores. En este sentido, Gimeno (1988) afirma: Esa epistemología implícita del profesor respecto del conocimiento es una parte sustancial de sus perspectivas profesionales, configuradas a lo largo de su experiencia, en la formación inicial como profesor e incluso como alumno. La calidad de la experiencia cultural que tienen los profesores va dejando un sedimento en ellos a lo largo de su formación, siendo la base de la valoración que harán del saber y de las actitudes, la ciencia, el conocer y la cultura. Perspectivas que pondrá en acción cuando él tenga que enseñarlo o guiar a los alumnos para que lo aprendan (p. 218). Existe pues una cadena de sucesivos refuerzos en las concepciones epistemológicas que manifiestan los profesores: de su experiencia como alumnos a la que adquieren en la formación inicial, y de ésta a la que interiorizan con una determinada manera de concebir y practicar la enseñanza. De ahí la importancia que numerosos autores conceden al tratamiento de las concepciones epistemológicas en la formación inicial y permanente (Hewson y Hewson, 1987; Gil, 1991). Son la «materia prima»o, si se prefiere, los obstáculos más relevantes para avanzar en la construcción de un conocimiento profesional significativo. A continuación, presentamos un análisis de nuestros datos en relación con el mismo propósito: aproximarnos al pensamiento de los profesores a través de lo que dicen y hacen.

\section{DE LA DIVERSIDAD DE CONCEPCIONES DE LOS PROFESORES A LOS NIVELES DE FORMULACIÓN DEL CONOCIMIENTO PROFESIONAL}

Durante los ultimos años (1986-1993) hemos realizado cuatro estudios empíricos que podemos considerar relevantes para la problemática que venimos tratando. En ellos, hemos trabajado con muestras, amplias y reducidas, de profesores en formación inicial y en ejercicio. Los instrumentos y las técnicas utilizadas en el tratamiento de los datos (ya presentadas en el primer artículo de esta serie) se resumen en la tabla I. Dado que todos ellos están sometidos a un mismo marco teórico de referencia (también descrito en el primer artículo) y que es inviable una descripción pormenorizada de los datos (pueden verse para ello las publicaciones referenciadas), los presentaremos de una manera conjunta, analizando cada una de las categorías que han sido seleccionadas (Anexo I del primer artículo) para orientar este trabajo: imagen de la ciencia, modelo didáctico personal, teoría subjetiva del aprendizaje y enfoque curricular (contenidos, metodología y evaluación).

En consonancia con otros estudios, detectamos, para las diferentes categorías estudiadas, una diversidad de concepciones que nos permiten establecer diferentes niveles de formulación en las concepciones de los profesores. Así pues, presentaremos, dentro de cada categoría, una posible hipótesis de progresión con:

a) un nivel de partida que suele ser más próximo a las tendencias mayoritarias del profesorado;

b) niveles intermedios que tratan de superar, a veces con planteamientos muy diferentes entre sí, los obstáculos que suponen dichas tendencias mayoritarias;

c) un nivel de referencia que trata de superar las dificultades que presentan las respuestas parciales de los niveles intermedios y que se aproxima al conocimiento profesional deseable (Porlán et al., 1996).

Desde nuestros planteamientos acerca de la organización y construcción del conocimiento profesional, esta forma de sintetizar los datos empíricos tiene utilidad para la práctica de la formación del profesorado (al igual que ocurre con los estudios de las concepciones de los alumnos), pues nos ofrece una hipótesis de qué obstáculos parecen estar impidiendo el tránsito hacia concepciones cada vez más evolucionadas acerca del conocimiento, su enseñanza y su aprendizaje en el contexto escolar. No obstante, no se trata de itinerarios cerrados a recorrer por todos los profesores, más bien se trata de referentes para el formador, que pueden y deben enriquecerse y contrastarse con los datos procedentes de la experimentación de estrategias y modelos formativos coherentes con estos supuestos.

\section{Imagen de la ciencia: predominio del empirismo}

En los estudios 2 y 3 se detectaron tres modelos en relación con la imagen de la ciencia: racionalismo, empirismo y relativismo, siendo el segundo el que se corresponde con aquellos factores que explican más porcentaje de varianza (Tabla II). Además, por lo que puede apreciarse, los futuros profesores presentaron una mayor diversidad de concepciones que los profesores en ejercicio, que se manifiestaron más próximos al empirismo. Esto es debido, probablemente, a que los primeros no tienen suficiente experiencia que les sirva para constrastar sus ideas y a que sus puntos de vista son poco estables al no tener criterios muy definidos.

Los resultados obtenidos en estos dos trabajos están en la línea de los descritos anteriormente por lo que se refiere a la tendencia más representativa. 
Tabla II

Interpretación de los factores obtenidos por los análisis de componentes principales de las declaraciones relacionadas con la imagen de la ciencia (INPECIP). Entre paréntesis se indica la varianza explicada por cada factor.

\begin{tabular}{|c|c|c|c|c|}
\hline \multicolumn{2}{|c|}{ IMAGEN DE LA CIENCIA } & \multicolumn{3}{|c|}{ ANÁLISIS DE COMPONENTES PRINCIPALES } \\
\hline & & FACTOR 1 & FACTOR 2 & FACTOR 3 \\
\hline \multirow[t]{2}{*}{$\begin{array}{l}\text { ESTUDIO } 2 \\
\text { (Porlán, 1989) }\end{array}$} & $\begin{array}{l}\text { Futuros profesores } \\
\text { de EGB }\end{array}$ & $\begin{array}{l}\text { Empirismo radical } \\
(13,35 \%)\end{array}$ & $\begin{array}{l}\text { Relativismo } \\
(10,07 \%)\end{array}$ & $\begin{array}{l}\text { Racionalismo } \\
(9,64 \%)\end{array}$ \\
\hline & Profesores de EGB & $\begin{array}{l}\text { Empirismo moderado } \\
(14,28 \%)\end{array}$ & $\begin{array}{l}\text { Empirismo moderado } \\
(13,07 \%)\end{array}$ & $\begin{array}{l}\text { Empirismo radical } \\
(12,00 \%)\end{array}$ \\
\hline $\begin{array}{l}\text { ESTUDIO } 3 \\
\text { (Martín, 1994) }\end{array}$ & $\begin{array}{l}\text { Futuros profesores } \\
\text { de EGB }\end{array}$ & $\begin{array}{l}\text { Empirismo moderado } \\
(15,87 \%)\end{array}$ & $\begin{array}{l}\text { Empirismo radical } \\
(13,06 \%)\end{array}$ & $\begin{array}{l}\text { Dimensión realista } \\
\text { y objetivista del } \\
\text { conocimiento } \\
(13,04 \%)\end{array}$ \\
\hline
\end{tabular}

Tabla III

Niveles de formulación sobre la imagen de la ciencia.

\begin{tabular}{|c|c|c|}
\hline \multicolumn{3}{|c|}{ IMAGEN DE LA CIENCIA } \\
\hline $\begin{array}{l}\text { RACIONALISMO } \\
\text { El modelo racionalista responde a } \\
\text { un punto de vista que considera que } \\
\text { el conocimiento es un producto de } \\
\text { la mente humana, generado a través } \\
\text { del rigor lógico y de la razón. Para } \\
\text { el racionalismo, el conocimiento no } \\
\text { está en la realidad ni se obtiene por } \\
\text { un proceso de observación de la } \\
\text { misma, ya que los sentidos humanos } \\
\text { inevitablemente deforman los } \\
\text { hechos y, por tanto, tergiversan la } \\
\text { realidad impidiendo el auténtico } \\
\text { conocimiento. Esta posición } \\
\text { intelectual se corresponde con una } \\
\text { forma de absolutismo no empirista. } \\
\text { (Porlán, 1989, p. 313) }\end{array}$ & $\begin{array}{l}\quad \text { EMPIRISMO RADICAL } \\
\text { Basada en la creencia de que la } \\
\text { observación de la realidad permite } \\
\text { obtener por inducción el } \\
\text { conocimiento objetivo y verdadero } \\
\text { que, como tal, es un reflejo de la } \\
\text { realidad (objetivismo, absolutismo } \\
\text { y realismo). } \\
\text { (Porlán, 1989, p. 315) } \\
\quad \text { EMPIRISMO MODERADO } \\
\text { Cercana a un inductivismo } \\
\text { matizado o a un cierto } \\
\text { falsacionismo experimentalista en } \\
\text { el que la hipótesis y la } \\
\text { experimentación sustituyen la mera } \\
\text { observación como eje fundamental } \\
\text { del proceso científico. } \\
\text { (Porlán, 1989, pp. 314-315) }\end{array}$ & $\begin{array}{l}\text { ALTERNATIVA } \\
\text { (Relativismo moderado, constructivismo } \\
\text { y evolucionismo) } \\
\text { Una nueva imagen de la ciencia } \\
\text { como actividad condicionada } \\
\text { social e históricamente, llevada a } \\
\text { cabo por científicos } \\
\text { (individualmente subjetivos pero } \\
\text { colectivamente críticos y } \\
\text { selectivos), poseedores de } \\
\text { diferentes estrategias } \\
\text { metodológicas que abarcan } \\
\text { procesos de creación intelectual, } \\
\text { validación empírica y selección } \\
\text { crítica, a través de las cuales se } \\
\text { construye un conocimiento } \\
\text { temporal y relativo, que cambia y } \\
\text { se desarrolla permanentemente. } \\
\text { (Porlán, 1989, p. 65) }\end{array}$ \\
\hline
\end{tabular}


En cuanto al estudio 1, la tendencia empirista se resume en los siguientes principios:

a) Principio de la neutralidad y autenticidad del conocimiento científico: El conocimiento está en la realidad y la ciencia es un reflejo cierto del mismo (realismo). Hay un método único y universal para acceder al conocimiento sin posibilidad de estar influenciado por la subjetividad (objetivismo). Este método parte de la observación, elaboración de hipótesis, experimentación y enunciado de teorías (inductivismo). Se trata de una concepción empirista-radical o experimental-inductiva (Aguirre, Haggerty y Linder, 1990). No obstante, puede darse una cierta influencia previa de las hipótesis en este proceso (empirismo moderado): es lo que Aguirre, Haggerty y Linder (1990) denominan concepción experimental-falsacionista.

b) Principio de la veracidad del conocimiento científico: Los conocimientos científicos, al ser obtenidos empíricamente, tienen un carácter absoluto y universal. Aunque, en determinados sujetos, se aprecia una cierta tensión con posiciones más relativistas, debido en parte al conocimiento de la existencia de diferentes teorías científicas sobre un mismo fenómeno a lo largo de la historia.

c) Principio de la superioridad del conocimiento científico: Expresa la idea de un cierto autoritarismo epistemológico al considerarlo, especialmente en el caso de las ciencias experimentales, una forma superior de conocimiento y al infravalorar el conocimiento más subjetivo y cotidiano.

No obstante, en este mismo estudio (estudio 1) se detectaron otras posiciones que no son propias de un empiris- mo epistemológico: una, que podemos identificar con planteamientos relativistas en la línea de lo detectado por Kouladis y Ogborn (1989), con una cierta influencia del sujeto en el proceso de elaboración del conocimiento (sus propias ideas e intereses, la influencia de las teorías en la observación, etc.) y con un carácter más provisional y evolutivo; y otra que podemos identificar con planteamientos más racionalistas.

En la tabla III podemos contemplar, de forma resumida, esta diversidad de concepciones acerca del conocimiento científico como diferentes niveles de formulación.

Por otra parte, el transfondo absolutista que está presente tanto en la visión empirista como en la racionalista de la ciencia (es decir, tanto en lo que los profesores suelen pensar como en lo que suelen hacer) es, desde nuestro punto de vista, el obstáculo más potente para el desarrollo de una epistemología constructivista (Porlán y Martín, 1996, p. 27). La visión del conocimiento científico como algo absoluto, objetivo, acabado, descontextualizado y neutral es el obstáculo epistemológico, el núcleo duro de las concepciones en la terminología de Astolfi (1993), que impide considerar el conocimiento escolar (y el propio conocimiento profesional) como un conocimiento epistemológicamente diferenciado y no como una reproducción enciclopédica, fragmentada y simplicada de las disciplinas, y el conocimiento de los alumnos como un conocimiento alternativo (y no como errores a reemplazar por el significado correcto). Desde nuestra propia experiencia, estos planteamientos pueden ponerse en cuestión en el proceso formativo, a partir del trabajo con hipótesis curriculares relacionadas con contenidos concretos (Porlán y Martín, 1996).

Tabla IV

Interpretación de los factores obtenidos por los ACP de las declaraciones relacionadas con el modelo didáctico personal (INPECIP). Entre paréntesis se indica la varianza explicada por cada factor.

\begin{tabular}{|c|c|c|c|c|}
\hline \multirow{2}{*}{\multicolumn{2}{|c|}{$\begin{array}{c}\text { MODELO DIDÁCTICO } \\
\text { PERSONAL }\end{array}$}} & \multicolumn{3}{|c|}{ ANÁLISIS DE COMPONENTES PRINCIPALES } \\
\hline & & & & \\
\hline \multirow[t]{2}{*}{$\begin{array}{l}\text { ESTUDIO 2 } \\
\text { (Porlán, 1989) }\end{array}$} & $\begin{array}{l}\text { Futuros profesores } \\
\text { de EGB }\end{array}$ & $\begin{array}{l}\text { Tecnológico } \\
(12,85 \%)\end{array}$ & $\begin{array}{l}\text { Tecnológico } \\
(11,14 \%)\end{array}$ & $\begin{array}{l}\text { Alternativo } \\
(10,57 \%)\end{array}$ \\
\hline & Profesores de EGB & $\begin{array}{l}\text { Tradicional } \\
(22,50 \%)\end{array}$ & $\begin{array}{l}\text { Alternativo } \\
(15,64 \%)\end{array}$ & $\begin{array}{l}\text { Tecnológico } \\
(9,78 \%)\end{array}$ \\
\hline $\begin{array}{l}\text { ESTUDIO } 3 \\
\text { (Martín, 1994) }\end{array}$ & $\begin{array}{l}\text { Futuros profesores } \\
\text { de EGB }\end{array}$ & $\begin{array}{l}\text { Alternativo- } \\
\text { tecnológico } \\
(20,02 \%)\end{array}$ & $\begin{array}{l}\text { Tecnológico } \\
(17,11 \%)\end{array}$ & $\begin{array}{l}\text { Tradicional } \\
(13,81 \%)\end{array}$ \\
\hline
\end{tabular}


Tabla V

Niveles de formulación sobre el modelo didáctico personal.

\begin{tabular}{|c|c|c|}
\hline \multicolumn{3}{|c|}{ MODELO DIDÁCTICO PERSONAL } \\
\hline $\begin{array}{l}\quad \text { TRADICIONAL } \\
\text { El enfoque tradicional representa una } \\
\text { concepción acientífica de los } \\
\text { procesos de enseñanza-aprendizaje, } \\
\text { según la cual, en el mejor de los } \\
\text { casos, basta con que el profesor } \\
\text { tenga una buena preparación en los } \\
\text { contenidos de la materia y unas } \\
\text { ciertas cualidades humanas acordes } \\
\text { con la actividad de enseñar para que } \\
\text { el sistema funcione. Cuando el } \\
\text { sistema fracasa, o bien se debe a que } \\
\text { el profesor no reúne los requisitos } \\
\text { mencionados, o bien a que los } \\
\text { alumnos son deficientes estudiantes o } \\
\text { tienen sus capacidades intelectuales } \\
\text { mermadas. En este enfoque didáctico, } \\
\text { el eje fundamental sobre el que } \\
\text { gravita la organización y el } \\
\text { desarrollo de las tareas de clase es el } \\
\text { eje temático de los contenidos, de ahí } \\
\text { la denominación que a veces recibe } \\
\text { de pedagogía por contenidos. } \\
\text { (Porlán, 1989, p. 325) }\end{array}$ & 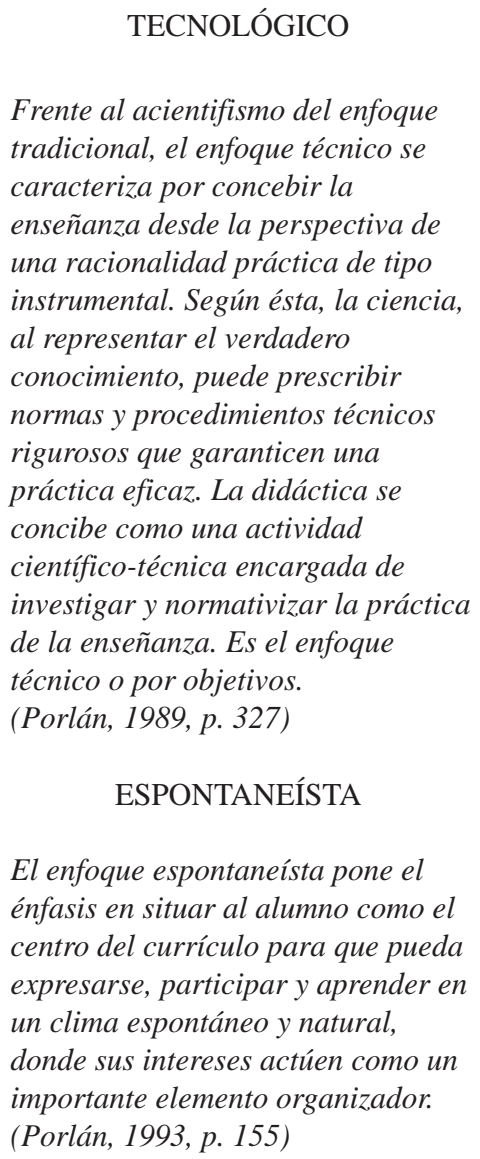 & $\begin{array}{l}\quad \text { ALTERNATIVO } \\
\text { La razón de asignarle un } \\
\text { apelativo tan ambiguo viene } \\
\text { motivada por el hecho de que no } \\
\text { disponemos aún de un referente } \\
\text { teórico consolidado que nos } \\
\text { permita unificar en un sólo } \\
\text { concepto-síntesis sus rasgos más } \\
\text { característicos. Nos referimos, } \\
\text { por ejemplo, a las dimensiones } \\
\text { relativizadoras, complejas e } \\
\text { investigativas que se sitúan entre } \\
\text { las concepciones crítica e } \\
\text { interpretativa de la teoría de la } \\
\text { enseñanza. } \\
\text { (Porlán, 1989, p. 328) }\end{array}$ \\
\hline
\end{tabular}

\section{Modelos didácticos: las alternativas al modelo tradicional}

La mayor representatividad de la concepción empirista de la ciencia no conlleva, en los sujetos estudiados, una homogeneidad en la manera de entender los procesos de enseñanza-aprendizaje. Los resultados revelan tres tendencias o modelos didácticos personales (Tabla IV):

a) Modelo tecnológico, identificado básicamente con los objetivos como eje estructurador de la práctica y como referente para evaluar el aprendizaje de los alumnos. Este modelo aparece en los factores que explican más porcentaje de varianza entre las muestras de futuros profesores en los estudios 2 y 3 .

También en el estudio 1 se detectó esta tendencia, que puede sintetizarse en el principio de la racionalidad científica del conocimiento didáctico, por el que se adopta una posición experimentalista en el estudio de los procesos de enseñanza-aprendizaje. La enseñanza se concibe como una actividad técnica que, en la medida en que asuma métodos más científicos, mejorará su calidad.

b) Modelo tradicional, que parece más representativo entre los profesores en activo, y que se centra en la transmisión verbal de contenidos disciplinares.

c) También se detectaron conjuntos de declaraciones que reflejan una concepción alternativa del proceso de enseñanza-aprendizaje, al resaltar su carácter complejo, la participación de los alumnos y el papel investigador del profesor.

Según esto, tal como hemos indicado en otros trabajos (Porlán y Martín, J., 1991; Porlán, 1993; Martín, R., 
Tabla VI

Interpretación de los factores obtenidos por los ACP de las declaraciones relacionadas con el aprendizaje (INPECIP). Entre paréntesis se indica la varianza explicada por cada factor.

\begin{tabular}{|c|c|c|c|c|}
\hline \multicolumn{2}{|c|}{$\begin{array}{l}\text { TEORÍA SUBJETIVA } \\
\text { DEL APRENDIZAJE }\end{array}$} & \multicolumn{3}{|c|}{ ANÁLISIS DE COMPONENTES PRINCIPALES } \\
\hline & & & & \\
\hline \multirow[b]{2}{*}{$\begin{array}{l}\text { ESTUDIO } 2 \\
\text { (Porlán, 1989) }\end{array}$} & $\begin{array}{l}\text { Futuros profesores } \\
\text { de EGB }\end{array}$ & $\begin{array}{l}\text { Apropiación formal } \\
\text { de significados } \\
(12,50 \%)\end{array}$ & $\begin{array}{l}\text { Asimilación } \\
\text { de significados } \\
(11,35 \%)\end{array}$ & $\begin{array}{l}\text { Apropiación } \\
\text { de significados } \\
(10,50 \%)\end{array}$ \\
\hline & Profesores de EGB & $\begin{array}{l}\text { Apropiación formal } \\
\text { de significados } \\
(20,85 \%)\end{array}$ & $\begin{array}{l}\text { Asimilación } \\
\text { de significados } \\
(15,42 \%)\end{array}$ & $\begin{array}{l}\text { Construcción } \\
\text { de significados } \\
(9,14 \%)\end{array}$ \\
\hline $\begin{array}{l}\text { ESTUDIO } 3 \\
\text { (Martín, 1994) }\end{array}$ & $\begin{array}{l}\text { Futuros profesores } \\
\text { de EGB }\end{array}$ & $\begin{array}{l}\text { Apropiación formal } \\
\text { de significados } \\
(16,45 \%)\end{array}$ & $\begin{array}{l}\text { Asimilación } \\
\text { de significados } \\
(16,41 \%)\end{array}$ & $\begin{array}{c}(*) \\
(13,81 \%)\end{array}$ \\
\hline
\end{tabular}

* En este caso, el factor contiene un número de declaraciones que consideramos insuficiente para inferir una determinada concepción del aprendizaje.

1995), se puede considerar el modelo didáctico de tipo tradicional (centrado o dependiente de los contenidos y del profesor) como un primer nivel de formulación cercano a la consideración cotidiana de lo que es enseñar. La crítica de este modelo, ya sea dirigida desde la falta de rigor (crítica científico-técnica) o desde la falta de participación (crítica ideológica), provoca dos tendencias alternativas al mismo: una tecnológica y otra espontaneísta. Ambas se sitúan en un nivel de formulación intermedio, pues intentan resolver los problemas que plantea el racionalismo y el enciclopedismo del modelo tradicional, trasladando el empirismo científico al terreno didáctico: la primera a través de procesos excesivamente cerrados y rígidos, y la segunda más ligada a la idea de descubrimiento inductivo y autónomo de los alumnos (Gil, 1983). Por último, en un nivel de mayor complejidad situaríamos un modelo didáctico de tipo complejo e investigativo (Tabla V).

\section{Teoría subjetiva del aprendizaje: de la apropiación formal a la construcción de significados}

En las concepciones de los profesores sobre el aprendizaje de los estudios 2 y 3 (Tabla VI), los factores que explican más porcentaje de la varianza se relacionan con la idea de que el alumno es una mente en blanco o tabla rasa, que recibe una información del profesor y que captará su significado (se apropiará de él) siempre que esté atento y no tenga ninguna disfunción; lo que denominaremos aprendizaje por apropiación formal de significados (Porlán, 1989). Sin embargo, esta concepción debe matizarse en el caso del estudio 3, dado que bastantes sujetos reconocen que los alumnos tienen concepciones espontáneas y que, para poder aprender, es necesario que el profesor «corrija» las ideas de los alumnos para ser sustituidas por las correctas. Es lo que Hollon y Anderson (1987) denominan orientación del aprendizaje como comprensión del contenido, según la cual, a partir de las explicaciones del profesor, los alumnos añaden conocimientos o corrigen los que ya tenían. Podemos entonces considerar que la concepción más representativa sobre el aprendizaje está «contaminada» por una idea en alza entre los profesores: los alumnos tienen ideas acerca del mundo que deben ser consideradas (otra cuestión es qué consideración didáctica merecen y qué hay que hacer con ellas).

También se detectaron factores próximos a una concepción que denominaremos aprendizaje por asimilación de significados (Porlán, 1989), según la cual, para aprender hay que estar personalmente implicado en el contenido del aprendizaje y relacionarlo con lo que ya se sabe al respecto; de esta manera se puede incorporar significativamente a la estructura cognitiva. Es lo que Hollon y Anderson (1987) denominan orientación de desarrollo conceptual y que también se detecta en el estudio de Aguirre, Haggerty y Linder (1990).

La muestra constituida por profesores de EGB en ejercicio presentó unos planteamientos más diversos, detectándose incluso conjuntos de declaraciones próximas a la idea de un aprendizaje por construcción de los significados. 
Tabla VII

Niveles de formulación sobre el aprendizaje.

\begin{tabular}{|c|c|c|}
\hline \multicolumn{3}{|c|}{ TEORÍA SUBJETIVA DEL APRENDIZAJE } \\
\hline $\begin{array}{l}\quad \text { APROPIACIÓN FORMAL } \\
\text { Conjunto de creencias bastante } \\
\text { generalizadas que conciben el hecho } \\
\text { de aprender como un acto de } \\
\text { apropiación cognitiva, mediante el } \\
\text { cual, el sujeto que aprende, toma del } \\
\text { exterior, ya sea de otra persona de un } \\
\text { texto escrito o de la propia realidad, } \\
\text { unos determinados significados. } \\
\text { Presupone que la comunicación de } \\
\text { significados es un proceso neutro y } \\
\text { objetivo donde los mensajes no sufren } \\
\text { alteraciones ni deformaciones en el } \\
\text { proceso que va desde el sujeto que } \\
\text { emite al sujeto que recibe. Presupone } \\
\text { también que de cada concepto, } \\
\text { proceso o dato, que es conveniente } \\
\text { enseñar y aprender, sólo existe un } \\
\text { unico significado correcto. El que va } \\
\text { a aprender algo lo hace porque, o no } \\
\text { posee dicho significado, o el que } \\
\text { posee es incorrecto. Esta idea sobre } \\
\text { el aprendizaje ha sido representada } \\
\text { por las metáforas del vaso vacío o de } \\
\text { la mente en blanco. } \\
\text { (Porlán, 1989, p. 337) }\end{array}$ & $\begin{array}{l}\quad \text { ASIMILACIÓN } \\
\text { En este punto de vista, lo relevante no } \\
\text { es capturar un significado como si } \\
\text { fuera un paquete de información que } \\
\text { alojáramos en una determinada } \\
\text { estantería de nuestra memoria para } \\
\text { ser usado cuando se considere } \\
\text { necesario. Lo relevante es asimilarlo, } \\
\text { hacerlo significativamente propio, } \\
\text { comprenderlo en profundidad, } \\
\text { incorporarlo a una estructura } \\
\text { cognitiva de carácter relacional. } \\
\text { Supone una actitud más activa del } \\
\text { sujeto. Para asimilar hay que querer } \\
\text { hacerlo, hay que estar interesado } \\
\text { desde uno mismo y predispuesto. Pero } \\
\text { asimilar supone también estar en } \\
\text { posesión de los significados previos y } \\
\text { colaterales que permitan realizar con } \\
\text { éxito las operaciones de ensamblaje } \\
\text { del nuevo significado. } \\
\text { (Porlán, 1989, pp. 339-340) }\end{array}$ & $\begin{array}{l}\quad \text { CONSTRUCCIÓN } \\
\text { La construcción de conocimientos es } \\
\text { un proceso en que el individuo y el } \\
\text { grupo no sólo desarrollan gradual y } \\
\text { progresivamente su particular } \\
\text { estructura de significados, sino que, } \\
\text { precisamente por ser un proceso en el } \\
\text { que el sujeto elabora los significados, } \\
\text { y no simplemente los toma o asimila, } \\
\text { también construyen singularmente el } \\
\text { camino específico de su evolución. No } \\
\text { hay, según esto, estructuras rígidas y } \\
\text { únicas de desarrollo prefijado, ni } \\
\text { metas finales obligadas en el proceso; } \\
\text { hay caminos personales y grupales, } \\
\text { influidos socialmente, que constituyen } \\
\text { desarrollos cognitivos } \\
\text { semiautónomos, sin referentes } \\
\text { absolutos y terminales que } \\
\text { necesariamente se tengan que } \\
\text { alcanzar. } \\
\text { Porlán, 1989, p. 342) }\end{array}$ \\
\hline
\end{tabular}

En la tabla VII pueden apreciarse los niveles de formulación que proponemos en relación con la manera de concebir el aprendizaje en el contexto escolar. En esta progresión, la concepción de que los alumnos «no saben nada» o de que sus ideas sólo son «errores» actúa a modo de obstáculo en la consideración de las concepciones de los alumnos como un conocimiento alternativo que ha de interactuar con el conocimiento escolar que consideremos deseable. Obstáculo que, a su vez, podemos considerar constitutivo de una concepción reduccionista y aditiva del sistema cognitivo humano (García, 1995).

\section{Enfoque curricular: la traslación del empirismo científico al terreno didáctico}

En los estudios anteriores no hemos hecho referencia a ningún contenido escolar concreto, puesto que se trataba de describir planteamientos generales sobre la ciencia, la enseñanza y el aprendizaje. Nos interesa ahora comentar las posibles relaciones entre la epistemología de los profesores y sus concepciones sobre la enseñanza de un campo conceptual concreto. Así, el estudio 4 se centró en otra característica: el enfoque curricular. Para ello, se realizó un análisis de contenido de los diseños de las unidades didácticas elaboradas por seis grupos de cuatro futuros profesores de EGB en una situación habitual de clase, durante un curso de formación inicial; la temática de referencia era la enseñanza del cambio químico en $8^{\circ}$ de EGB (14 años).

En este estudio, los enfoques curriculares que se derivan de los modelos didácticos ya descritos (tradicional, tecnológico, espontaneísta y alternativo) nos han servido de referencia para dotar de significado a las diferentes subcategorías tratadas en el mismo (contenidos, metodología y evaluación), lo que ha orientado el análisis del contenido de los diseños de las unidades didácticas (Tabla VIII).

Los resultados muestran que los contenidos son un conjunto acumulativo y fragmentario de conceptos, le- 
Tabla VIII

Niveles de formulación en las diferentes categorías curriculares.

\begin{tabular}{|c|c|c|c|}
\hline \multirow{2}{*}{$\begin{array}{l}\text { SUBCATEGORÍAS } \\
\text { (Aspectos estudiados) }\end{array}$} & \multicolumn{3}{|c|}{ ENFOQUE CURRICULAR (Niveles de formulación) } \\
\hline & Enfoque tradicional. & $\begin{array}{l}\text { Tendencia tecnológica. } \\
\text { Tendencia espontaneísta. }\end{array}$ & $\begin{array}{l}\text { Enfoque alternativo } \\
\text { (constructivista e } \\
\text { investigativo). }\end{array}$ \\
\hline $\begin{array}{l}\text { CONTENIDOS } \\
\text { - Nivel de formulación } \\
\text { - Amplitud y diversidad } \\
\text { - Organización }\end{array}$ & $\begin{array}{l}\text { El contenido } \\
\text { del conocimiento escolar } \\
\text { como adaptación del } \\
\text { conocimiento disciplinar. }\end{array}$ & $\begin{array}{l}\text { El contenido del } \\
\text { conocimiento escolar como } \\
\text { adaptación del conocimiento } \\
\text { disciplinar. } \\
\text {---------------------- } \\
\text { El contenido del } \\
\text { conocimiento escolar como } \\
\text { adaptación contextual del } \\
\text { conocimiento cotidiano. }\end{array}$ & $\begin{array}{l}\text { El contenido del } \\
\text { conocimiento escolar como } \\
\text { reelaboración e integración } \\
\text { de conocimientos que } \\
\text { proceden de diversas } \\
\text { fuentes. }\end{array}$ \\
\hline $\begin{array}{l}\text { METODOLOGÍA } \\
\text { - Papel didáctico de las } \\
\text { concepciones de los alumnos } \\
\text { - Caracterización de las } \\
\text { actividades } \\
\text { - Interacción } \\
\text { profesor-alumnos }\end{array}$ & $\begin{array}{l}\text { Basada en la transmisión } \\
\text { verbal de conocimientos } \\
\text { por parte del profesor } \\
\text { mientras los alumnos } \\
\text { atienden o realizan } \\
\text { actividades de } \\
\text { comprobación de lo } \\
\text { explicado. }\end{array}$ & $\begin{array}{l}\text { Basada en la versión fuerte } \\
\text { (inductivista) del empirismo. } \\
\text { Los objetivos como hilo } \\
\text { conductor de las actividades. } \\
\text {------------------ } \\
\begin{array}{l}\text { Basada en la versión débil } \\
\text { del empirismo. Los intereses } \\
\text { de los alumnos como hilo } \\
\text { conductor de las actividades. }\end{array}\end{array}$ & $\begin{array}{l}\text { La investigación de } \\
\text { problemas de interés } \\
\text { potencial es lo que da } \\
\text { sentido a las actividades, } \\
\text { siendo las ideas de los } \\
\text { alumnos un referente } \\
\text { continuo del proceso. }\end{array}$ \\
\hline $\begin{array}{l}\text { EVALUACIÓN } \\
\text { - Finalidad } \\
\text { - Contenido } \\
\text { - Instrumentos }\end{array}$ & $\begin{array}{l}\text { La evaluación como } \\
\text { calificación para comprobar } \\
\text { que los alumnos se han } \\
\text { apropiado de los conceptos } \\
\text { explicados. }\end{array}$ & $\begin{array}{l}\text { La evaluación como medida } \\
\text { del grado de consecución de } \\
\text { los objetivos. } \\
------------ \\
\text { La evaluación como } \\
\text { participación en la dinámica } \\
\text { de la clase. }\end{array}$ & $\begin{array}{l}\text { La evaluación como } \\
\text { investigación para ajustar la } \\
\text { enseñanza y el aprendizaje } \\
\text { (es decir, la hipótesis de } \\
\text { conocimiento escolar } \\
\text { deseable y la evolución real } \\
\text { de las concepciones de los } \\
\text { alumnos). }\end{array}$ \\
\hline
\end{tabular}

yes y teorías cuya estructura responde a la versión simplificada y dogmática del conocimiento disciplinar que ofrecen los libros de texto. Los contenidos se organizan linealmente, en forma de listados, sin establecerse relaciones entre ellos. Por otra parte, se indica qué contenidos se pretenden enseñar pero no la formulación que se considera deseable para los alumnos. No obstante, junto con esta tendencia mayoritaria hay algunos elementos que dan alguna complejidad al contenido de la enseñanza, sobre todo, al intentar responder a los posibles intereses de los alumnos sobre los cambios químicos (aplicación y utilidad de estos fenómenos). Sin embargo, en ningún caso organizan los contenidos en torno a problemas relevantes para el contexto escolar, de manera que puedan integrarse y reelaborarse los conocimientos procedentes de fuentes diversas. Asimismo, tampoco proponen diferentes niveles de formulación para el concepto de cambio químico, ni establecen relaciones entre conceptos de un mismo nivel; entre otras razones porque no han tenido una formación disciplinar ni didáctica que les haya preparado para ello.

En la metodología se detecta una tendencia mayoritaria basada en la mezcla de dos elementos: la aplicación didáctica de una versión empirista del método científico (actividades de observación de fenómenos para inferir conceptos) y la explicación del profesor para hacer comprender dichos conceptos. En esta tendencia las ideas de los alumnos o no se tienen en cuenta o se consideran requisitos conceptuales que los alumnos han de poseer. Las interacciones profesor-alumnos son más bien una relación unidireccional que va del papel direc- 
tivo del profesor al papel del alumno (en el sentido de que realiza las actividades que plantea el profesor). Asimismo, junto con estos elementos mayoritarios se combinan otros minoritarios pero que configuran dos tendencias metodológicas distintas en grupos diferentes:

a) Una centrada en el interés y la participación de los alumnos buscando todo aquello capaz de sosprenderles. El profesor cumple así un papel de preparador de todas aquellas actividades que tengan un potencial motivador para los alumnos (noticias, películas, representaciones teatrales, fiestas de disfraces...). Todo parece indicar que lo que se busca principalmente es una actitud favorable hacia el aprendizaje. De ahí que las ideas de los alumnos se consideren como una manifestación de su interés por el tema, pero no como un conocimiento que hay que facilitar que evolucione.

b) Otra centrada en las concepciones de los alumnos, en las discusiones y el contraste entre ellos, y en el papel del profesor como orientador de todas esas ideas hacia un conocimiento compartido.

No obstante, hemos de insistir en que se trata de elementos parciales que diferencian las propuestas metodológicas de estos grupos en relación con las de los demás, y no de modelos propiamente dichos (espontaneísta en un caso, constructivista en el otro).

La secuencia de actividades prototípica podría ser: Observación de fenómenos $\longrightarrow$ Inferencia de conceptos $\longrightarrow$ Explicación del profesor como refuerzo $\longrightarrow$ Aplicación a otras situaciones.

Todo parece indicar que la evaluación es coherente con un modelo didáctico tradicional (comprobación final de aprendizajes conceptuales mediante pruebas escritas) pero contaminado a veces con elementos más propios de una tendencia tecnológica (diagnóstico inicial y final del nivel de conocimientos) o espontaneísta (no-inclusión de pruebas escritas, importancia de las actitudes de los alumnos), o incluso más compleja (proceso continuo de mejora, tanto del aprendizaje como de la propia programación, a través de la información que suministran fuentes muy diversas).

En resumen, la interacción entre su conocimiento sobre el cambio químico y el conocimiento didáctico general ha permitido a los futuros profesores elaborar una propuesta curricular que se caracteriza por:

a) la utilización de los libros de texto como referente fundamental para la selección de los contenidos; también de los materiales curriculares centrados en las actividades, como referente fundamental para la selección de las mismas;

b) una secuencia lineal y acumulativa de contenidos, organizados según la lógica disciplinar características de los libros de texto;

c) una secuencia cerrada de actividades de observación en el laboratorio que, dirigidas por el profesor, permiten a los alumnos inferir los conceptos; d) una serie de instrumentos, especialmente pruebas escritas, para comprobar si los alumnos han adquirido los conocimientos previamente establecidos.

Así pues, las concepciones didácticas generales detectadas en el etudio 3 se contaminan con planteamientos más simplistas acerca de la enseñanza (el profesor como fuente de conocimiento verdadero) y del aprendizaje (los alumnos se apropian del conocimiento que está en la realidad y en las explicaciones del profesor) al descender al terreno de lo concreto; es decir, al elaborar una propuesta didáctica sobre el cambio químico. Entendemos que en ello puede influir el hecho de que los estudiantes-profesores rechacen la enseñanza transmisiva que han recibido; por eso, manifiestan ciertos planteamientos generales alternativos, si bien éstos son en realidad el producto de la interacción entre este rechazo y la influencia recibida por formación ambiental mientras fueron alumnos. Dicho en otros términos: aunque lo rechacen, al no haber recibido otro tipo de enseñanza, sólo cuestionan los aspectos más evidentes y no sus fundamentos. Y, por otra parte, puede suceder que no dispongan aún de suficientes elementos teórico-prácticos para trasladar dichos planteamientos generales novedosos a la enseñanza de un campo conceptual concreto.

El transfondo absolutista en la concepción empirista del conocimiento, detectada en el estudio 3 , les conduce a plantear que un proceso de inferencia (actividades basadas en la observación de fenómenos) dirigido por el profesor, y reforzado por sus explicaciones, llevará a los alumnos a adquirir el conocimiento previamente establecido; al tiempo, corrigen sus errores o llenan las posibles lagunas en sus conocimientos previos. Así pues, se confirma el obstáculo absolutista que representan sus concepciones epistemológicas. Ello les hace optar por un enfoque más tecnológico que espontaneísta a la hora de plantearse el conocimiento escolar, en general, y sobre este campo conceptual, en particular.

En definitiva, la transposición o transformación didáctica que realizan los futuros profesores consiste en una reproducción de la visión acumulativa, fragmentaria y no interactiva de los cambios químicos que ellos mismos sustentan. En este proceso influye fundamentalmente el tipo de transposición que se detecta, a su vez, en los textos escolares (simplificación de los contenidos disciplinares, organización de los mismos atendiendo a la lógica disciplinar y visión empirista y enciclopédica del conocimiento científico), ya que son utilizados como fuentes de información privilegiada para determinar los contenidos a enseñar.

\section{UNA APROXIMACIÓN A LA EPISTE- MOLOGÍA DE LOS PROFESORES}

Como ya adelantábamos en la revisión de otros estudios, también hemos tratado de hacer un planteamiento más global de las concepciones para aproximarnos a lo que sería una teoría específica sobre el conocimiento dado, 
asimilado o construido en el marco y en el contexto específicamente escolar (Porlán, 1989, p. 366). Así, las categorías estudiadas se consideran ahora como diferentes dimensiones de una teoría sobre el conocimiento escolar.

Del análisis de componentes principales realizado sobre el conjunto de las declaraciones del INPECIP en los estudios 2 y 3 , se obtuvieron una serie de factores que se categorizaron en cuatro tendencias hipotéticas acerca de la epistemología escolar, y que sintetizan las observadas en los análisis parciales que ya hemos comentado (Tabla IX). Éstas son:

a) Una concepción del conocimiento escolar como un producto formal, que es reflejo de una posición racionalista en relación con la naturaleza de la ciencia, un modelo didáctico tradicional, una concepción del aprendizaje basada en la apropiación formal de significados y una metodología de enseñanza fundamentada en la trans- misión del conocimiento ya elaborado por el profesor.

b) Una concepción del conocimiento escolar como proceso técnico, que es coherente con una imagen empirista de la ciencia, un modelo didáctico científico-técnico, una concepción del aprendizaje por asimilación de significados y una metodología basada en la actividad del alumno aplicando los pasos del método científico.

c) Una concepción del conocimiento escolar como un proceso espontáneo, que participa también de un empirismo más moderado, de una concepción del aprendizaje por asimilación y muy especialmente de una metodología basada en la actividad espontánea del alumno. Este enfoque pretende una mezcla imposible entre la objetividad de lo empírico y la subjetividad de lo espontáneo (Porlán, 1989, p. 377).

d) Una concepción del conocimiento escolar como un proceso complejo, que intenta superar las dicotomías

Tabla IX

Niveles de formulación en la teoría sobre el conocimiento escolar.

\begin{tabular}{|c|c|c|}
\hline \multicolumn{3}{|c|}{ EPISTEMOLOGÍA ESCOLAR } \\
\hline PRODUCTO FORMAL & PROCESO TÉCNICO & PROCESO COMPLEJO \\
\hline $\begin{array}{l}\text { Una dinámica institucional muy } \\
\text { directiva, evaludora y sancionadora } \\
\text { que basa casi exclusivamente su } \\
\text { actividad en un discurso verbal del } \\
\text { profesor es un reflejo de una cierta } \\
\text { identificación del conocimiento con } \\
\text { su formulación literal, como un } \\
\text { producto acabado del que interesa } \\
\text { fundamentalmente su envoltura. } \\
\text { (Porlán, 1989, p. 368) }\end{array}$ & $\begin{array}{l}\text { Una dinámica basada en la } \\
\text { programación detallada y secuenciada } \\
\text { de actividades empíricas por el } \\
\text { profesor expresa quizás una reducción } \\
\text { del conocimiento a la eficacia de un } \\
\text { proceso técnico. } \\
\text { (Porlán, 1989, p. 369) } \\
\qquad \text { PROCESO ESPONTÁNEO } \\
\text { Una situación escolar donde el profesor } \\
\text { tienda regularmente a apoyar las } \\
\text { actividades observacionales y } \\
\text { manipulativas que interesan a sus } \\
\text { alumnos, sin establecer con ellos un } \\
\text { intercambio dirigido y estable de } \\
\text { construcción conceptual, es probable } \\
\text { que implique una simplificación de los } \\
\text { procesos relacionados con el desarrollo } \\
\text { de los conocimientos, al reducirlos casi } \\
\text { exclusivamente al interés espontáneo } \\
\text { del sujeto que conoce. } \\
\text { (Porlán, 1989, p. 369) }\end{array}$ & $\begin{array}{l}\text { Una visión complejizadora del } \\
\text { conocimiento escolar no puede } \\
\text { considerar el conocimiento previo del } \\
\text { alumno como algo incorrecto y el } \\
\text { conocimiento disciplinar reflejado en } \\
\text { los contenidos como algo } \\
\text { absolutamente cierto. Una visión de } \\
\text { este tipo ha de considerar ambos } \\
\text { como diferentes variantes } \\
\text { conceptuales, cuya validez será } \\
\text { relativa a los problemas que son } \\
\text { relevantes para el alumno, para el } \\
\text { profesor o, por ejemplo, para el } \\
\text { científico. La validez de un } \\
\text { conocimiento es adaptativa a un } \\
\text { medio ecosociológico determinado y } \\
\text { a los problemas ambientales } \\
\text { característicos del mismo. Construir } \\
\text { el conocimiento no significa } \\
\text { construirlo espontáneamente o } \\
\text { autoritariamente, sino } \\
\text { interactivamente a través de la } \\
\text { comunicación y negociación } \\
\text { democrática. } \\
\text { (Porlán, 1989, p. 379) }\end{array}$ \\
\hline
\end{tabular}


entre lo objetivo y lo subjetivo, lo racional y lo espontáneo, lo absoluto y lo relativo. Que el conocimiento sea relativo no significa que una comunidad como la escolar no pueda seleccionar aquellos conocimientos que puedan resolver los problemas y satisfagan los intereses de sus miembros. Ciertas declaraciones que hacen referencia a los intereses de los alumnos, sus conocimientos previos, el planteamiento de problemas... son algunos de los rasgos característicos de esta tendencia alternativa.

Los resultados obtenidos entre el profesorado en ejercicio muestran una gran diversidad, dependiendo de los años de experiencia profesional y de la especialización. Sus concepciones epistemológicas más representativas se identifican con una concepción del conocimiento como algo formal a transmitir por el profesor y a aprender por los alumnos. Junto a esta tendencia, mayoritaria entre los sujetos de mayor experiencia, los especializados en ciencias conciben el conocimiento escolar como reductible a la eficacia de un proceso técnico muy dirigido por el profesor, al programar las actividades prácticas de los alumnos y al transmitir el conocimiento correcto. Asimismo, aunque como posición minoritaria, también se aprecia una corriente de opinión más cercana a concepciones relativistas, abiertas y complejas de lo escolar.

Para la muestra de los futuros profesores, el rechazo a la enseñanza tradicional y la adopción de una concepción empirista del conocimiento no se corresponde necesariamente con una perspectiva didáctica espontaneísta, sino más bien con la idea de que: La enseñanza ha de ser un proceso técnico y dirigido que conduzca a los alumnos, a través de unas actividades prácticas (observación, experimentación, etc.) perfectamente programadas, a descubrir el conocimiento previamente establecido por el profesor (Porlán, 1989, p. 397). Dicho en otros términos: Los estudiantes de magisterio manifiestan un rechazo significativo hacia una concepción del conocimiento como mero producto formal. Para ellos, el conocimiento está asociado a los procesos empíricos y prácticos más que a un academicismo racional, y esto les lleva a propugnar una metodología de trabajo en el aula basada en los procesos científicos y en el contacto con la realidad (Porlán, 1989, p. 402). No obstante, los contenidos siguen ocupando un papel central en la enseñanza. Lo que parece ponerse en cuestión para los estudiantes-profesores es la manera en que el profesor consigue que los alumnos aprendan y, en este sentido, como ya hemos reflejado anteriormente, un proceso inductivo parece ser la garantía para conseguirlo. En definitiva, los resultados confirman que la tendencia mayoritaria entre los futuros profesores traslada el empirismo científico al terreno didáctico. De esta forma, el complejo proceso de enseñanza-aprendizaje se desarrolla a través de la participación de los alumnos en actividades prácticas en contacto con la realidad y el laboratorio para conseguir sustituir sus ideas erróneas por las correctas. Éstas serán, en última instancia, explicadas por el profesor.

Cada una de las tendencias detectadas puede contemplarse como una hipotética progresión en el conocimien-

Tabla X

Hipótesis de progresión del conocimiento profesional sobre el conocimiento escolar y valores de las diferentes categorías estudiadas.

\begin{tabular}{|c|c|c|c|c|c|c|}
\hline \multirow{2}{*}{$\begin{array}{l}\text { Epistemología } \\
\text { escolar }\end{array}$} & \multirow{2}{*}{$\underset{\text { ciencia }}{\text { Imagen de la }}$} & \multirow{2}{*}{$\begin{array}{c}\text { Modelo } \\
\text { didáctico } \\
\text { personal }\end{array}$} & \multirow{2}{*}{$\begin{array}{c}\text { Teoría } \\
\text { subjetiva del } \\
\text { aprendizaje }\end{array}$} & \multicolumn{3}{|c|}{ Enfoque curricular } \\
\hline & & & & Contenidos & Metodología & Evaluación \\
\hline $\begin{array}{l}\text { Conocimiento } \\
\text { escolar como } \\
\text { producto } \\
\text { formal }\end{array}$ & Racionalismo & Tradicional & $\begin{array}{l}\text { Apropiación } \\
\text { formal } \\
\text { de } \\
\text { significados }\end{array}$ & $\begin{array}{l}\text { Reproducción } \\
\text { y } \\
\text { simplificación } \\
\text { disciplinar }\end{array}$ & $\begin{array}{c}\text { Transmisión } \\
\text { verbal del } \\
\text { profesor }\end{array}$ & $\begin{array}{l}\text { Calificación } \\
\text { (exámenes) }\end{array}$ \\
\hline 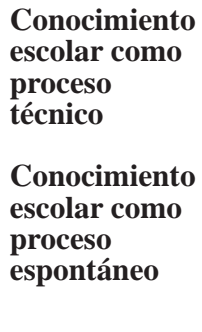 & Empirismo & Espontaneísta & $\begin{array}{l}\text { Asimilación } \\
\text { de } \\
\text { significados }\end{array}$ & $\begin{array}{c}\text { Adaptación } \\
\text { disciplinar }\end{array}$ & $\begin{array}{c}\text { Secuencia } \\
\text { cerrada de } \\
\text { actividades } \\
\\
\text { Secuencia } \\
\text { orientada por } \\
\text { los intereses } \\
\text { de los alumnos }\end{array}$ & $\begin{array}{l}\text { Medida del } \\
\text { grado de } \\
\text { consecución de } \\
\text { los objetivos }\end{array}$ \\
\hline $\begin{array}{l}\text { Conocimiento } \\
\text { escolar como } \\
\text { proceso } \\
\text { complejo }\end{array}$ & $\begin{array}{l}\text { Relativismo } \\
\text { moderado }\end{array}$ & $\begin{array}{l}\text { Alternativo, } \\
\text { constructivista } \\
\text { e investigativo }\end{array}$ & $\begin{array}{c}\text { Construcción } \\
\text { de } \\
\text { significados }\end{array}$ & $\begin{array}{l}\text { Reelaboración } \\
\text { e integración } \\
\text { de } \\
\text { conocimientos } \\
\text { diversos }\end{array}$ & $\begin{array}{l}\text { Investigación } \\
\text { escolar de } \\
\text { problemas } \\
\text { significativos }\end{array}$ & $\begin{array}{c}\text { Investigación } \\
\text { de la } \\
\text { hipótesis } \\
\text { curricular }\end{array}$ \\
\hline
\end{tabular}


to profesional sobre el conocimiento escolar, que integra los diferentes niveles de formulación que hemos ido proponiendo a lo largo del trabajo (Tabla X). Es necesario explicar que no tiene por qué darse una coherencia entre todas las dimensiones propuestas. Por ejemplo, en el estudio 4 se detecta que los futuros profesores trasladan el empirismo científico a la metodología didáctica, pero los contenidos a enseñar no son una adaptación, sino una reproducción simplificada y enciclopédica del conocimiento disciplinar.

\section{CONSIDERACIONES FINALES}

A lo largo de dos artículos hemos pretendido ofrecer una visión de conjunto del trabajo de reflexión teórica y de contrastación empírica en torno al conocimiento profesional de los profesores, realizado en los últimos años en el marco del Proyecto Curricular IRES.

Desde nuestro punto de vista, la construcción del conocimiento profesional se verá facilitada en la medida en que el formador disponga de una hipótesis sobre la posible progresión desde el conocimiento que «de hecho» manifiestan los profesores hacia un conocimiento deseable para mejorar realmente la enseñanza y el aprendizaje.

Por último, queremos manifestar nuestro deseo e interés de que la perspectiva epistemológica adoptada, entre otras posibles, para el análisis del conocimiento profesional, contribuya a transformar realmente nuestras propias prácticas en la formación del profesorado, mejorando nuestro saber profesional, y el de los profesores en formación y en ejercicio que trabajan con nosotros. Pero además, esperamos, igualmente, que sea de utilidad para el debate sobre los problemas profesionales de los profesores.

\section{NOTA}

${ }^{*}$ Esta publicación es resultado parcial del proyecto PB94-1449 financiado por la DGICYT.

\section{REFERENCIAS BIBLIOGRÁFICAS}

AGUIRRE, J.M., HAGGERTY, S.M. y LINDER, C.J. (1990): Student-teachers' conceptions of science, teaching and learning: a case study in preservice science education. International Journal of Science Education, 12(4), pp. 381-390.

ASTOLFI, J.P. (1993). Los obstáculos en el aprendizaje de conceptos en ciencias: la forma de franquearlos didácticamente, en Diez años de investigación e innovación en enseñanza de las ciencias. Madrid: Centro de Publicaciones del Ministerio de Educación y Ciencia. CIDE.

BARQUÍN, J. (1991). La evolución del pensamiento del profesor. Revista de Educación, 294, pp. 245-274.

BAUCH, P.A. (1984). The Impact of Teachers' instructional Beliefs on their Teaching: Implications for Research and Practice. Reunión anual de la AERA. New Orleans, Abril.

BUITINK, J. y KEMME, S. (1986). Changes in StudentsTeacher Thinking. European Journal of Teacher Education, 9(1), pp. 75-84

COTHAM, J.C. y SMITH, E.L. (1981). Development and Validation of the Conceptions of Scientific Theories Test. Journal of Research in Science Teaching, 18(5), pp. 387-396.
ELBAZ,F. (1981). The Teachers' Practical Knowledge: Report of a Case Study. Curriculum Inquiry, 11(1), pp. 43-71.

GALLAGHER, J.J. (1993). Six Views of Teaching Science. An Invitation to Reflection and Discussion. Michigan State University. Documento multicopiado.

GARCÍA, J.E. (1995). La transición desde un pensamiento simple hasta un pensamiento complejo en la construcción del conocimiento escolar. Investigación en la Escuela, 27, pp. 7-20.

GIL, D. (1983). Tres paradigmas básicos en la enseñanza de las ciencias. Enseñanza de las Ciencias, 1 (1), pp. 26-33.

GIL, D. (1991). ¿Qué hemos de saber y saber hacer los profesores de ciencias? (Intento de síntesis de las aportaciones de la investigación didáctica). Enseñanza de las Ciencias, 9 (1), pp. 69-77.

GIL, D. (1993). Aportaciones de la investigación en didáctica de las ciencias a la formación y actividad del profesorado. Qurriculum, 6-7, pp. 45-66.

GIMENO, J. (1988). El currículo: una reflexión sobre la práctica. Madrid: Morata. 
GORDON, D. (1984). The Image of Science, Technological Consciousness and Hidden Curriculum. Curriculum Inquiry, 14(4), pp. 367-400.

GUSTAFSON, B.J. y ROWELL, P.M. (1995): Elementary preservice teachers: constructing conceptions about learning science, teaching science and the nature of science. International Journal of Science Education, 17(5), 589-605.

HALKES, R. y DEIJKRES, R. (1983). Teachers' Teaching Criteria, en Halkes, R. y Olson, J.K.. Teacher Thinking: a New Perspective on Persisting Problems in Education. Lisse: Swets y Zeitlinger

HASHWEH, M.Z. (1996). Effects of Science Teachers' Epistemological Beliefs in Teaching. Journal of Research in Science Teaching, 33(1), pp. 47-63.

HEWSON, P.W. y HEWSON, M.G. (1987). Science teachers' concepctions of teaching: Implications for teacher education. International Journal of Science Education, 9(4), pp. 425440.

HOLLON, R.E. y ANDERSON, C.W. (1987). Teachers' beliefs about students' learning processes in science: self-reinforcing belief systems. Documento presentado en Annual Meeting of the AERA. Washington, D.C.

KOULADIS, V. y OGBORN, J. (1989): Philosophy of science: an empirical study of teachers' views. International Journal of Science Education, 11(2), pp. 173-184.

KOULADIS, V. y OGBORN, J. (1995): Science teachers' philosophical assumptions: how well do we understand them? International Journal of Science Education, 17(3), pp. 273-283.

LEDERMAN, N.G. (1992): Students' and Teachers' Conceptions of the Nature of Science: A Review of the Research. Journal of Research in Science Teaching, 29(4), pp. 331-359.

MARRERO, J. (1994). Las teorías implícitas del profesorado: vínculo entre la cultura y la práctica de la enseñanza, en Rodrigo, M.J., Rodríguez, A. y Marrero, J. (eds.). Las teorías implícitas. Una aproximación al conocimiento cotidiano. Madrid: Visor

MARTÍN DEL POZO, R. (1994). El conocimiento del cambio químico en la formación inicial del profesorado. Estudio de las concepciones disciplinares y didácticas de los estudiantes de magisterio. Tesis doctoral inédita. Universidad de Sevilla.

MARTÍN DEL POZO, R. (1995). El conocimiento escolar y profesional sobre el cambio químico en el diseño curricular Investigando Nuestro Mundo. Investigación en la Escuela, 27, pp. 39-48.

OBERG, A. (1986). Using Construct Theory as a Basis for Research into Teacher Professional Development. Journal of Curriculum Studies, 19(1), pp. 55-65.

PÉREZ GÓMEZ, A.I. y GIMENO, J. (1992). El pensamiento pedagógico de los profesores: un estudio empírico sobre la incidencia de los cursos de aptitud pedagógica (CAP) y de la experiencia profesional en el pensamiento de los profesores. Investigación en la Escuela, 17, pp. 51-73.

POPE, M. y GILBERT, J. (1983): Personal Experience and the Construction of Knowledge in Science. Science Education, 67(2), 193-203. (Trad. cast. 1988, La experiencia personal y la construcción del conocimiento en ciencias, en: Porlán, R., García, J.E. y Cañal, P. Constructivismo y enseñanza de las ciencias. Sevilla: Díada).

POPE, M.L y SCOTT, E.M. (1983). Teachers' Epistemology and Practice, en Halkes, R. y Olson, J.K. Teacher Thinking: a New Perspective on Persisting Problems in Education. Lisse: Swets y Zeitlinger. (Trad. cast. 1988, La epistemología y la práctica de los profesores, en Porlán, R., García, J.E. y Cañal, P. Constructivismo y enseñanza de las ciencias. Sevilla: Díada).

PORLÁN, R. (1989): Teoría del conocimiento, teoría de la enseñanza y desarrollo profesional. Las concepciones epistemológicas de los profesores. Tesis doctoral. Universidad de Sevilla.

PORLÁN, R. (1993): Constructivismo y escuela. Sevilla: Díada.

PORLÁN, R. (1994): Las concepciones epistemológicas de los profesores: el caso de los estudiantes de magisterio. Investigación en la Escuela, 22, pp. 67-84.

PORLÁN, R. (1995): Las creencias pedagógicas y científicas de los profesores. Enseñanza de las Ciencias de la Tierra, 3(1), pp. 7-13.

PORLÁN, R. y LÓPEZ, J.I. (1993). Constructivismo en ciencias: pensamiento del alumnado versus pensamiento del profesorado. Qurriculum, 6-7, pp. 91-107.

PORLÁN, R. y MARTÍN, J. (1991). El diario del profesor. Un recurso para la investigación en el aula. Sevilla: Díada.

PORLÁN, R. y MARTÍN, R. (1996). Ciencia, profesores y enseñanza: unas relaciones complejas. Alambique, 8, pp. 23-32.

PORLÁN, R., AZCÁRATE, P., MARTÍN, R.,MARTÍN, J. y RIVERO, A. (1996). Conocimiento profesional deseable y profesores innovadores: Fundamentos y principios formativos. Investigación en la Escuela, 29.

SMITH, D. y NEALE, D. (1991). The Construction of SubjetMatter Knowledge in Primary Science Teaching, en Brophy, J. (ed.). Advances in Research on Teaching. Vol. 2. JAI Press.

VICTOR, J.B. (1976). Relation between Teacher Belief and Personality in Four Samples of Teacher Trainees. Journal of Experimental Education, 45, pp. 4-9.

WHELING, L.J. y CHARTERS, W.W. (1969). Dimensions of Teacher Beliefs about the Teaching Process. American Educational Research Journal, 6(1), pp. 7-30. 